International Journal of Current Advanced Research

ISSN: O: 2319-6475, ISSN: P: 2319 - 6505, Impact Factor: SJIF: 5.995

Available Online at www.journalijcar.org

Volume 6; Issue 4; April 2017; Page No. 3026-3028

DOI: http://dx.doi.org/10.24327/ijcar.2017.3028.0169

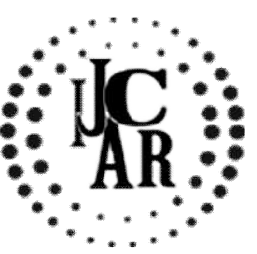

Research Article

\title{
AWARENESS OF BONE TUMOR IN MIDDLE AGED POPULATION
}

\section{Priadarsini T*}

Saveetha Dental College, 162, Poonamallee high road, Chennai-77

\begin{tabular}{l}
\hline A R T I C L E I N F O \\
\hline Article History: \\
Received $10^{\text {th }}$ January, 2017 \\
Received in revised form $19^{\text {th }}$ February, 2017 \\
Accepted $16^{\text {th }}$ March, 2017 \\
Published online $28^{\text {th }}$ April, 2017 \\
\hline
\end{tabular}

Key words:

Bone tumor, Bone cancer, awareness, Bone Biopsy.

\begin{abstract}
A B S T R A C T
Objective: To evaluate the awareness of etiology, classification, signs and symptoms, treatment and prevention of bone tumour.

Methods: A cross-sectional questionnaire survey was carried out to assess the knowledge on bone tumors in middle aged population. A specially designed questionnaire consisting of 13 close-ended questions was said to assess the awareness on bone tumor among the middle aged population.

Result: $63 \%$ of the population have stated that they have knowledge about bone tumor. Many people are confused with the terms bone tumor and bone cancer.

Conclusion: This study has shown that the participants have poor knowledge about bone tumor be it about causes, symptoms, diagnosis and treatment. Therefore it is important to create awareness and educate the community and to remove the misconceptions associated with ignorance through community based educational/awareness campaign.
\end{abstract}

Copyright $₫ 2017$ Priadarsini T. This is an open access article distributed under the Creative Commons Attribution License, which permits unrestricted use, distribution, and reproduction in any medium, provided the original work is properly cited.

\section{INTRODUCTION}

When cells divide abnormally and uncontrollably they form a mass or lump of tissue. This lump is called a tumor.The neoplastic growth of tissue in bone is bone tumor. As the tumor grows, abnormal tissue displaces the healthy tissue. Tumors can be benign or malignant. Benign bone tumors won't spread to other parts of the body and are unlikely to be fatal and cancerous. But they can grow and compress your healthy bone tissue.Other tumors are malignant, meaning they're cancerous.(1) Malignant bone tumors can cause cancer to spread throughout the body. Benign bone tumors include:

- Osteochondromas

- Nonossifying fibroma unicameral

- Giant cell tumors

- Enchondroma

- Fibrous dysplasia

- Aneurysmal bone cyst

Types of Malignant bone tumors are:

- Osteosarcoma

- Ewing sarcoma Family of tumors (ESFTs)

- Chondrosarcoma(2)

\section{Classification}

Bone tumors may be classified as "primary tumors", which originate in bone or from bone-derived cells and tissues, and

*Corresponding author: Priadarsini T

Saveetha Dental College, 162, Poonamallee high road, Chennai-77 "secondary tumors" which originate in other sites and spread (metastasise) to the skeleton. Carcinomas of the prostate, breasts, lungs, thyroid, and kidneys are the carcinomas that most commonly metastasise to bone. Secondary malignant bone tumors are estimated to be 50 to 100 times as common as primary bone cancers.(3)

\section{Primary tumors}

Primary tumors of bone can be divided into benign tumors and cancers. Common benign bone tumors may be neoplastic, developmental, traumatic, infectious, or inflammatory in etiology. Some benign tumors are not true neoplasms, but rather, represent hamartomas, namely the osteochondroma. The most common locations for many primary tumors, both benign and malignant include the distal femur and proximal tibia (around the knee joint). Primary tumors also include benign bone tumors.

\section{Secondary tumors}

As benign bone tumors do not metastasize, all secondary bone tumors are metastaticleisonswhich have spread from other organs, most commonly carcinomas of the breast, lung, and prostate.Reliable and valid statistics on the incidence, prevalence, and mortality of malignant bone tumors are difficult to come by, particularly in the oldest (those over 75 years of age), because carcinomasthat are widely metastatic to bone are rarely ever curable, biopsies to determine the origin of the tumor in cases like this are rarely done. $(3,4)$ This article deals with the knowledge and awareness of middle aged population on bone tumors. 


\section{MATERIALS AND METHODS}

A cross-sectional questionnaire survey was carried out to assess the knowledge on bone tumors in middle aged population. A specially designed questionnaire consisting of 13 close-ended questions was said to assess the awareness on bone tumor among the middle aged population. The questionnaire was printed and distributed to the participants. The identity of the participants was maintained anonymous. The total responses were 100 in number.

\section{RESULTS}

$63 \%$ of the population have stated that they have knowledge about bone tumor. Many people are confused with the terms bone tumor and bone cancer. About $87 \%$ of the people have replied that both bone tumor and bone cancer are same. Most of the people are unaware of the causes of bone tumor $(80 \%)$

\section{CAUSES OF BONE TUMOR}

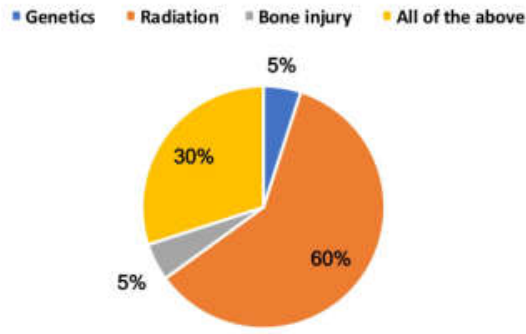

Fig 1 Causes of bone tumor

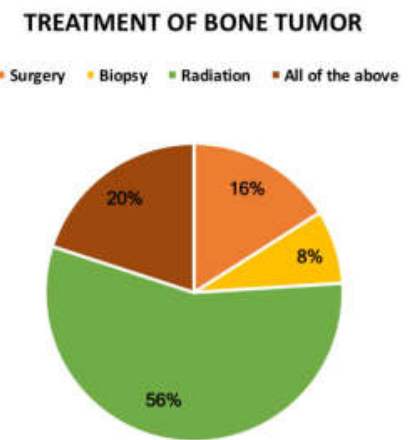

Fig 4 Treatment of bone tumor

Table 1 Awareness of bone tumor in middle aged population

\begin{tabular}{ccccc}
\hline & Causes & Symptoms & Diagnosis & Treatment \\
\hline AWARE & $20 \%$ & $10 \%$ & $5 \%$ & $25 \%$ \\
UNAWARE & $80 \%$ & $90 \%$ & $95 \%$ & $75 \%$ \\
\hline
\end{tabular}

Majority of the participants are unaware of the symptoms and diagnostics either. It is well evident from the above table.

\section{DISCUSSION}

Bone tumors may be benign or malignant, and differentiation may be difficult. Statistically, most bone tumors are benign. If the tumor does prove to be malignant, major resection or amputation with or without adjuvant therapy may be required. Malignant bone tumors may spread uncontrollably and result in death. Benign tumors may be locally aggressive and can recur even after surgical removal, at times requiring amputation for local control. Any bone tumor may weaken the bone and result in pathologic fracture. Treatment options include observation with additional X-rays taken at regular intervals to monitor any progressive change, further scans or biopsy. The most exact diagnostic technique is biopsy to obtain tissue for pathologic examination. $(5,6)$

Despite the availability of advanced imaging methods such as $\mathrm{CT}$ and MR imaging, with their ever increasing number of detectors and strength of the magnetic field, the diagnosis of a tumor or tumorlike lesion of bone still depends on the conventional radiograph. (7) By paying attention to the age of the patient, the location of the lesion, and the radiographic features of the lesion, the interpreter will be led to a short differential, if not the single correct, diagnosis.(8)

Bone tumors, one of the least common neoplasms, account for less than 0.2 percent of all cancers. The clinical, radiographic, and pathological understanding and classification of these rare tumors has slowly developed over the past several decades.

\section{DIAGNOSIS OF BONE TUMOR}

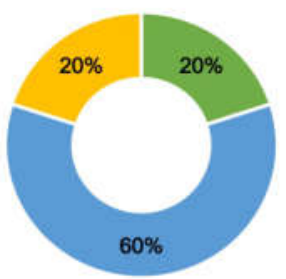

Fig 2 Diagnosis of bone tumor
SYMPTOMS OF BONE TUMOR

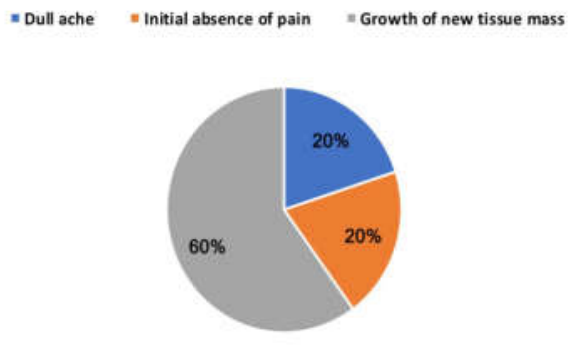

Fig 3 Symptoms of bone tumor
But the awareness among the middle aged population is far less than expected.(9)Till now there is no established national screening program for bone tumor in the country. In the present study we found that only $63 \%$ of the respondents were aware of breast cancer as a disease. Those who were aware were of higher socio-economic strata or the more educated.(10)

\section{CONCLUSION}

This study has shown that the particpants have poor knowledge about bone tumor be it about causes, symptoms, diagnosis and treatment. Therefore it is important to create awareness and educate the community and to remove the misconceptions associated with ignorance through community based educational/awareness campaign. Early warning signs, significance of a painless lump need to be emphasised. Educating health care workers is also very important aspect. We also have to keep in mind only campaigns will not be enough, information need to be disseminated in a form which is appealing to the community.

\section{Reference}

1. Jeon DG, Song WS, Kong CB, Kim JR, Lee SY. MFH of Bone and Osteosarcoma Show Similar Survival and Chemosensitivity. ClinOrthopRel Res 469; 584-90.

2. Rosenthal, Daniel I.; Hornicek, Francis J.; Torriani, Martin; Gebhardt, Mark C.; Mankin, Henry J. (200310-01).

3. Rimondi, Eugenio; Mavrogenis, Andreas F.; Rossi, Giuseppe; Ciminari, Rosanna; Malaguti, Cristina; 
Tranfaglia, Cristina; Vanel, Daniel; Ruggieri, Pietro (2011-08-14). "Radiofrequency ablation for non-spinal osteoid osteomas in 557 patients". European Radiology. 22 (1): 181-188.

4. Callstrom, Matthew R.; Dupuy, Damian E.; Solomon, Stephen B.; Beres, Robert A.; Littrup, Peter J.; Davis, Kirkland W.; Paz-Fumagalli, Ricardo; Hoffman, Cheryl; Atwell, Thomas D. (2013-0301). "Percutaneous image-guided cryoablation of painful metastases involving bone". Cancer. 119 (5): 1033-1041.

5. Howard D. Dorfman and BogdanCzerniak. : Bone tumors; 1261 pp., illustrated. St. Louis, Mosby, 1998.

6. Mungo, David V.; Zhang, Xinping; O'Keefe, Regis J.; Rosier, Randy N.; Puzas, J. Edward; Schwarz, Edward M. (2002). "COX-1 and COX-2 expression in osteoid osteomas". Journal of Orthopaedic Research.

7. Weber, Marc-André; Sprengel, Simon David; Omlor, Georg W.; Lehner, Burkhard; Wiedenhöfer, Bernd; Kauczor, Hans-Ulrich; Rehnitz, Christoph (2015-0425). "Clinical long-term outcome, technical success, and cost analysis of radio frequency ablation for the treatment of osteoblastomas and spinal osteoid osteomas in comparison to open surgical resection"
8. Dupuy, Damian E.; Liu, Dawei; Hartfeil, Donna; Hanna, Lucy; Blume, Jeffrey D.; Ahrar, Kamran; Lopez, Robert; Safran, Howard; DiPetrillo, Thomas (2010-02-15). "Percutaneous radio frequency ablation of painful osseous metastases"

9. Goetz, Matthew P.; Callstrom, Matthew R.; Charboneau, J. William; Farrell, Michael A.; Maus, Timothy P.; Welch, Timothy J.; Wong, Gilbert Y.; Sloan, Jeff A.; Novotny, Paul J. (2004-0115). "Percutaneous Image-Guided Radiofrequency Ablation of Painful Metastases Involving Bone: A Multicenter Study"

10. Tong, Daphne; Gillick, Laurence; Hendrickson, Frank R. (1982-09-01). "The palliation of symptomatic osseous metastases final results of the study by the radiation therapy oncology group". Cancer. 50 (5): 893-899.

\section{How to cite this article:}

Priadarsini T (2017) ' Awareness Of Bone Tumor In Middle Aged Population', International Journal of Current Advanced Research, 06(04), pp. 3026-3028.

DOI: http://dx.doi.org/10.24327/ijcar.2017.3028.0169 